\title{
Matching Illness Expectations with Clinical Reality
}

Ann Fam Med 2013;11:iii. doi:10.1370/afm.1485.

$\mathrm{T}$ The Annals of Family Medicine encourages readers to develop a learning community of those seeking to improve health care and health through enhanced primary care. You can participate by conducting a RADICAL journal club and sharing the results of your discussions in the Annals online discussion for the featured articles. RADICAL is an acronym for Read, Ask, Discuss, Inquire, Collaborate, Act, and Learn. The word radical also indicates the need to engage diverse participants in thinking critically about important issues affecting primary care and then acting on those discussions. ${ }^{1}$

\section{HOW IT WORKS}

In each issue, the Annals selects an article or articles and provides discussion tips and questions. We encourage you to take a RADICAL approach to these materials and to post a summary of your conversation in our online discussion. (Open the article online and click on "TRACK Comments: Submit a response.") You can find

discussion questions and more information online

at: http://www.AnnFamMed.org/AJC/.

\section{CURRENT SELECTION}

\section{Article for Discussion}

Ebell MH, Lundgren J, Youngpairoj S. How long does a cough last? Comparing patient expectations with data from a systematic review of the literature. Ann Fam Med. 2013;11(1):5-13.

\section{Discussion Tips}

An important and under-appreciated role of the savvy clinician is to help patients to match their illness expectations with what is likely to happen. This study finds a huge mismatch between what the general public expects about the course of acute illnesses with cough, and how long acute coughs last on average. The study also identifies personal characteristics associated with expectations for shorter than usual cough duration and expectations that antibiotics will help. How can we use this knowledge?

\section{Discussion Questions}

- What question is asked by this study and why does it matter?

- How does this study advance beyond previous research and clinical practice on this topic?

- How strong is the study design for answering the question? How helpful is it to bring together the 2 sources of data (population survey and systematic literature review)?

- To what degree can the findings be accounted for by:

1. How patients were selected, excluded, or lost to follow-up?

2. How the main variables were measured?

3. Confounding (false attribution of causality because 2 variables discovered to be associated actually are associated with a 3 rd factor)?

4. Chance?

5. How the findings were interpreted?

- What are the main study findings?

- How comparable are the study samples (for the survey and the literature review) to similar patients in your practice? What is your judgment about the transportability of the findings?

- What contextual factors are important for interpreting the findings?

- How might this study change your practice? Policy? Education? Research?

- Who are the constituencies for the findings, and how they might be engaged in interpreting or using the findings?

- What are the next steps in interpreting or applying the findings in clinical or public health settings?

-What researchable questions remain?

\section{References}

1. Stange KC, Miller WL, McLellan LA, et al. Annals Journal Club: it's time to get RADICAL. Ann Fam Med. 2006;4(3):196-197. http:// annfammed.org/cgi/content/full/4/3/196. 